\title{
Desain Wireless Sensor Network dan Webserver untuk Pemetaan Titik Api pada Kasus Kebakaran Hutan
}

\author{
Irwan Candra Dwinata, Muhammad Rivai, Eko Setijadi \\ Jurusan Teknik Elektro, Fakultas Teknologi Industri, Institut Teknologi Sepuluh Nopember (ITS) \\ Jl. Arief Rahman Hakim, Surabaya 60111 \\ e-mail:muhammad_rivai@ee.its.ac.id, ekoset@ee.its.ac.id, irwan.candra12@mhs.ee.its.ac.id
}

\begin{abstract}
Abstrak - Kebakaran hutan merupakan bencana yang dapat merusak lingkungan dan mengancam kelangsungan hidup hewan dan manusia. Proses pemadaman kebakaran hutan menjadi lebih mudah apabila kebakaran dapat dideteksi dengan cepat saat besarnya api masih terkontrol. Teknologi Wireless Sensor Network (WSN) dapat diaplikasikan dalam sistem pendeteksi dini kebakaran hutan dan dapat me-monitoring kondisi suatu area secara realtime. Tujuan dari penelitian ini adalah dilakukannya komunikasi Wireless Sensor Network antara node sensor dan webserver untuk memetakan titik api kebakaran hutan. Pada penelitian ini digunakan tiga node sensor dan satu webserver dengan menggunakan modul $x$ bee $\mathrm{s} 1$ dan protokol digimesh untuk membentuk jaringan yang terhubung secara wireless. Webserver diimplementasikan pada raspberry pi 2. Hasil pengujian menunjukkan setiap node sensor dapat mengirimkan sinyal kebakaran kepada webserver. Jarak maksimum antar modul xbee s1 adalah 28 meter dengan sinyal RSSI local sebesar $\mathbf{- 5 7} \mathbf{~ d B m}$ dan sinyal RSSI remote sebesar $-60 \mathrm{dBm}$. Node sensor yang tidak terjangkau langsung dengan webiserver akan mengirimkan sinyal secara berurutan ke node sensor yang lebih dekat untuk menyampaikan sinyal ke webserver. Webserver dapat menyimpan kondisi setiap node sensor kedalam database dan memetakan area kebakaran yang terintegrasi dengan google maps.
\end{abstract}

Kata Kunci-Google Maps, Node Sensor, Pemetaan Kebakaran, Webserver, Wireless Sensor Network.

\section{PENDAHULUAN}

$\mathrm{K}$ EBAKARAN hutan merupakan bencana yang dapat dicegah dan dikendalikan dengan penanganan yang terencana, menyeluruh, terpadu dan berkelanjutan. Pemerintah Indonesia melalui Departemen Kehutanan sudah melakukan usaha untuk mencegah kebakaran hutan, diantaranya dengan melakukan patroli kawasan hutan, pengamatan pada menara pengawas, sampai penggunaan citra satelit [1]. Namun pengawasan tersebut masih belum bisa mendeteksi kebakaran dengan cepat. Misalnya saja penggunaan teknologi citra satelit yang hanya dapat menyediakan gambar pada suatu daerah yang sama di bumi setiap dua hari sekali. Hal ini merupakan jeda waktu yang lama untuk mendeteksi kebakaran hutan, selain itu kualitas gambar dari satelit juga terpengaruh oleh cuaca [2]. Semakin lama proses pendeteksian kebakaran, maka proses pemadaman menjadi semakin sulit dilakukan serta menimbulkan dampak yang semakin besar, misalnya kerusakan ekologi yang semakin luas serta dampak kabut asap yang membahayakan kesehatan makhluk hidup.
Salah satu faktor penting dalam pemadaman kebakaran hutan adalah proses komunikasi untuk melaporkan peringatan kebakaran secepat mungkin dan informasi lokasi titik api yang akurat saat terjadi kebakaran hutan [1]. Semakin cepat kebakaran hutan dapat dideteksi, maka proses pemadaman kebakaran yang dilakukan menjadi semakin mudah, karena kondisi api masih dalam fase terkendali untuk dipadamkan. Perkembangan teknologi Wireless Sensor Network (WSN) dalam beberapa tahun terakhir memungkinkan teknologi ini untuk diaplikasikan dalam membuat pendeteksi dini kebakaran hutan. Sifat WSN ini adalah dapat me-monitoring suatu area pemantauan secara realtime.

Pada penelitian ini dilakukan pembuatan sistem komunikasi dalam pelaporan dan peringatan kebakaran hutan berbasis elektronik dengan mendesain suatu Wireless Sensor Network (WSN) untuk pemetaan titik api. Penelitian ini berfokus pada bagaimana mendesain jaringan komunikasi data antar node sensor pemberi peringatan kebakaran hutan dengan suatu webserver. Node sensor akan berada dalam posisi tersebar dan saling berkomunikasi dalam satu jaringan agar dapat mengirimkan data sampai kepada webserver. Saat terjadi sinyal peringatan kebakaran dari salah satu node sensor, maka data peringatan tersebut diteruskan oleh node sensor yang berdekatan untuk dapat sampai ke webserver. Pada webserver akan dilakukan pengolahan data untuk memberikan interface kepada user mengenai area yang terdampak api saat terjadi kebakaran. Dengan desain komunikasi yang berbasis elektronik tersebut, maka peringatan kebakaran dapat dilaporkan dengan cepat kepada pihak yang terkait dalam menangani kebakaran.

\section{DASAR TEORI}

\section{A. Xbee}

Xbee merupakan sebuah modul komunikasi radio yang diproduksi oleh Digi International. Modul Xbee dapat melakukan komunikasi antara satu dengan lainnya tanpa melalui kabel (wireless). Modul xbee cocok digunakan pada aplikasi-aplikasi yang memerlukan komunikasi antar modul yang tersebar, namun memiliki kesulitan apabila dihubungkan melalui kabel.

Xbee diproduksi dalam varian Xbee reguler dan Xbee Pro pada frekuensi $2.4 \mathrm{GHz}$. Perbedaan dari keduanya terletak pada 
Tabel 1

Jangkauan Modul Xbee

\begin{tabular}{lrrr}
\hline \hline \multicolumn{1}{c}{ Jenis Xbee } & $\begin{array}{c}\text { Jangkauan Line } \\
\text { Of Sight }\end{array}$ & Arus Tx & Arus $R x$ \\
\hline $\begin{array}{l}\text { Xbee 2.4Ghz S1 } \\
\text { Reguler }\end{array}$ & $90 \mathrm{~m}$ & $45 \mathrm{~mA}$ & $50 \mathrm{~mA}$ \\
Xbee 2.4 S1 Ghz Pro & $1.6 \mathrm{~km}$ & $250 \mathrm{~mA}$ & $55 \mathrm{~mA}$ \\
$\begin{array}{l}\text { Xbee 2.4 S1 Ghz Pro } \\
\text { International J varian }\end{array}$ & $1 \mathrm{~km}$ & $150 \mathrm{~mA}$ & $55 \mathrm{~mA}$ \\
$\begin{array}{l}\text { Xbee Pro 900 Mhz } \\
\text { S3B }\end{array}$ & $14.5 \mathrm{~km}$ & $215 \mathrm{~mA}$ & $29 \mathrm{~mA}$ \\
Xbee 868 Mhz S8 & $4 \mathrm{~km}$ & $48 \mathrm{~mA}$ & $27 \mathrm{~mA}$ \\
\hline \hline
\end{tabular}

jarak jangkauan antara 2 modul xbee. Modul xbee pro menggunakan daya pancar yang lebih besar, sehingga jarak jangkauan xbee pro lebih jauh dibandingkan dengan xbee reguler. Xbee pro juga memiliki harga yang lebih mahal daripada xbee reguler. Selain frekuensi $2.4 \mathrm{GHz}$, xbee juga mengeluarkan varian dengan frekuensi $900 \mathrm{MHz}$ dan frekuensi $868 \mathrm{MHz}$. Perbedaan jarak jangkauan antar modul xbee dapat dilihat pada tabel 1 [3].

\section{B. Protokol Digimesh}

Pada sistem komunikasi wireless sensor network, proses untuk routing data merupakan hal yang penting. Routing data ini cocok apabila menerapkan jaringan mesh. Salah satu protokol komunikasi jaringan mesh bernama protokol digimesh. Protokol ini dikembangkan oleh Digi International. Protokol ini merupakan pengembangan dari protokol Zigbee. Dalam membuat jaringan mesh, setiap node memiliki hubungan yang homogen, yaitu setiap node dapat memiliki kemampuan untuk melakukan routing data. Sehingga jaringan ini juga disebut peer-to-peer mesh networking. Gambaran dari protokol digimesh ini dapat dilihat pada gambar 1 [4].

Protokol digimesh ini memiliki kelebihan dalam membuat jaringan mesh, yaitu:

$>$ Setiap node bersifat homogen dan dapat melakukan routing data

$>$ Proses routing data menggunakan AODV (Ad hoc OnDemmand Vector Routing)

DN Digi Mesh Nodes

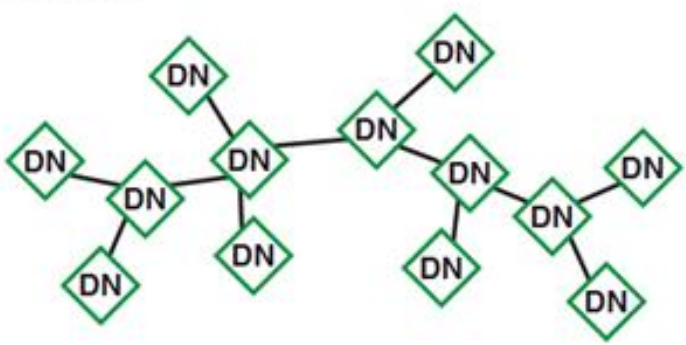

Gambar 1 Protokol Digimesh

Proses pembuatan tabel routing data hanya dilakukan saat dibutuhkan

$>$ Node dapat dihubungkan dan dicopot dari jaringan dengan mudah

$>$ Menggunakan ACK untuk memastikan pengiriman data [5].

\section{Mikrokontroller}

Mikrokontroller STM32F103C8 merupakan golongan STM32 berbasis ARM Cortex M3 prosesor 32 bit.
Mikrokontroller ini termasuk dalam kategori performa menengah pada golongan STM32. Mikrokontroller STM32F103C8 memiliki frekuensi clock maksimum sebesar 72 MHz. Memiliki 64 Kbyte flash memory dan 20 Kbyte SRAM, serta tegangan suplai 2 Volt sampai 3.6 Volt. Pinout dari perangkat mikrokontroller STM32F103C8 dengan 48 pin dapat dilihat pada gambar 2 [6].

Beberapa fitur yang dimiliki mikrokontroller STM32F103C8 yaitu:

$>$ Memiliki 7 timer

$>$ Mendukung interface komunikasi 2 buah I2C, 3 buah USART, CAN, USB

$>$ 7-channel DMA controller

$>$ Debug mode menggunakan Serial Wire Debug(SWD) dan interface JTAG

\section{Raspberry pi 2}

Raspberry pi 2 merupakan sebuah mini komputer yang diperkenalkan pada Februari 2015. Performa Raspberry pi 2 didukung oleh prosessor Broadcom BCM2836 yang merupakan generasi prosesor berbasis ARM Cortex-A7 quad core 900MHz. Raspberry pi 2 ini memiliki kapasitas RAM sebesar 1 GB. Dengan dimensi modul 85 x 56 x $17 \mathrm{~mm}$ dan disuplai oleh tegangan $5 \mathrm{~V}$ dan arus $2 \mathrm{~A}$ yang dipasang dengan menggunakan Micro USB [7]. Perangkat raspberry pi dapat dilihat pada gambar 3.

Fitur tambahan yang terdapat pada raspberry yaitu:

$>$ Memiliki Slot Micro SD

$>\quad$ Memiliki 40 Pin GPIO (General Purpose Input/Output)

$>\quad$ Multiple Port meliputi: 4 USB port, Full HDMI, 4 pole Stereo output dan komposit video port, CSI camera port, dan DSI display port.

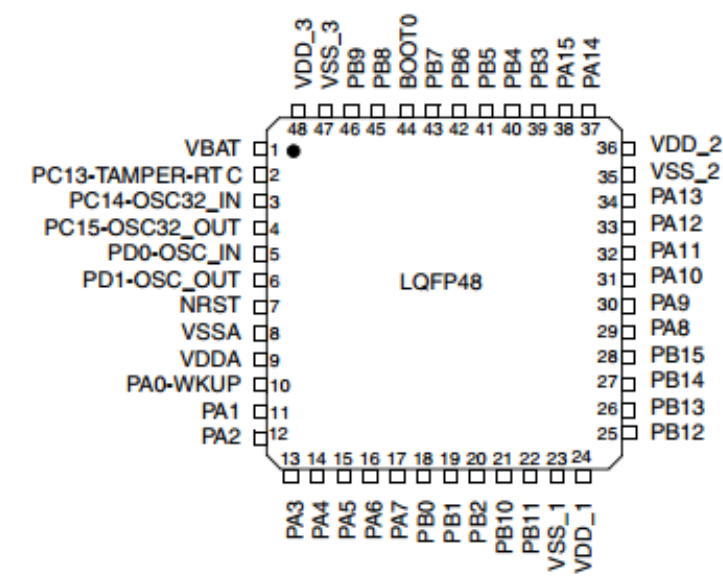

Gambar 2 Mikrokontroller STM32F103C8 pinout

GPIO Pinout Diagram

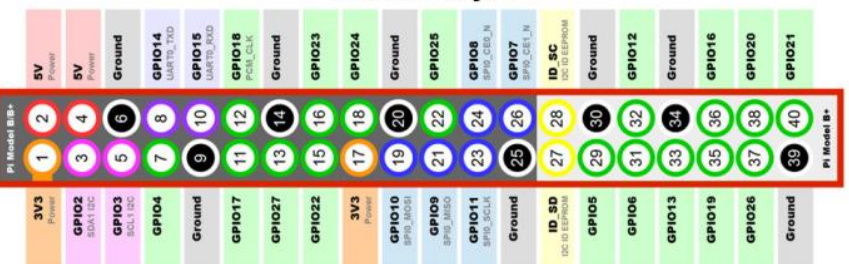

(a) 


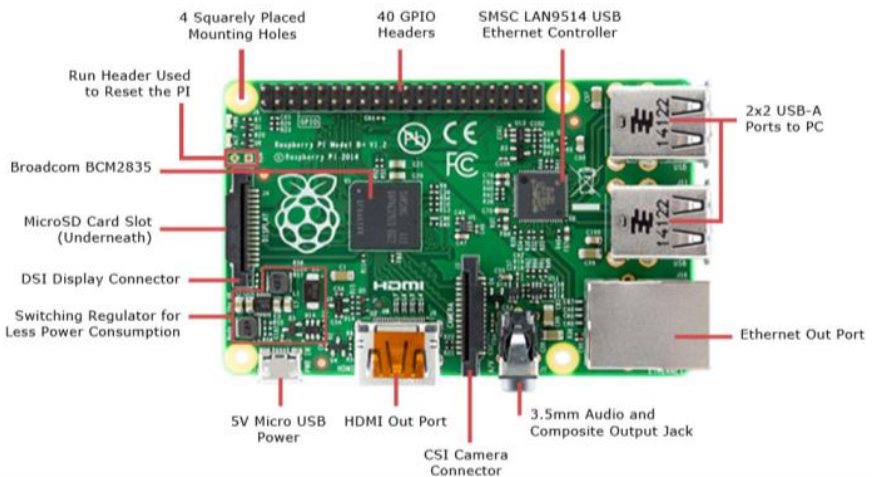

(b)

Gambar 3 (a) Diagram Pinout GPIO (b) Raspberry pi 2

\section{PERANCANGAN SISTEM}

\section{A. Cara Kerja Sistem}

Secara garis besar, sistem akan memiliki beberapa node sensor dan sebuah webserver yang terhubung dalam sebuah jaringan wireless agar dapat memetakan titik api pada kasus kebakaran. Posisi node sensor akan tersebar pada area pemantauan dan memiliki jarak yang bervariasi terhadap webserver. Cara kerja seperti ini dapat dilihat pada gambar 4.

\section{B. Pengujian Komunikasi Sistem}

Node sensor yang tersebar pada area pemantauan memiliki jarak yang bervariasi. Kondisi tersebut dibedakan menjadi 2 bagian. Pertama yaitu node sensor yang berada pada jangkauan modul komunikasi radio maka node sensor dapat mengirim sinyal kebakaran kepada webserver secara langsung. Kedua yaitu node sensor yang berada jauh dari webserver sehingga untuk mengirimkan sinyal kebakaran, node sensor yang jauh

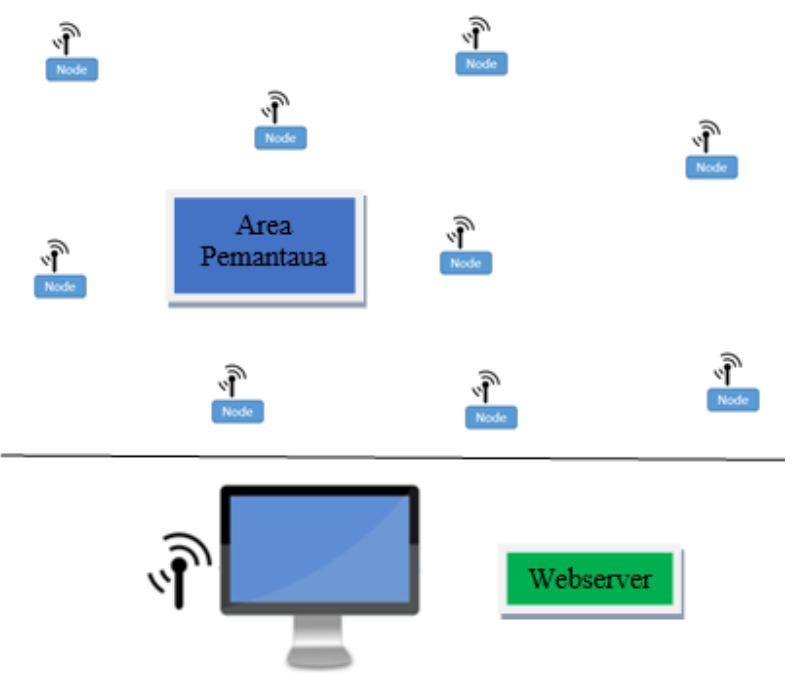

Gambar 4 Posisi Sebaran Node Sensor dan Webserver

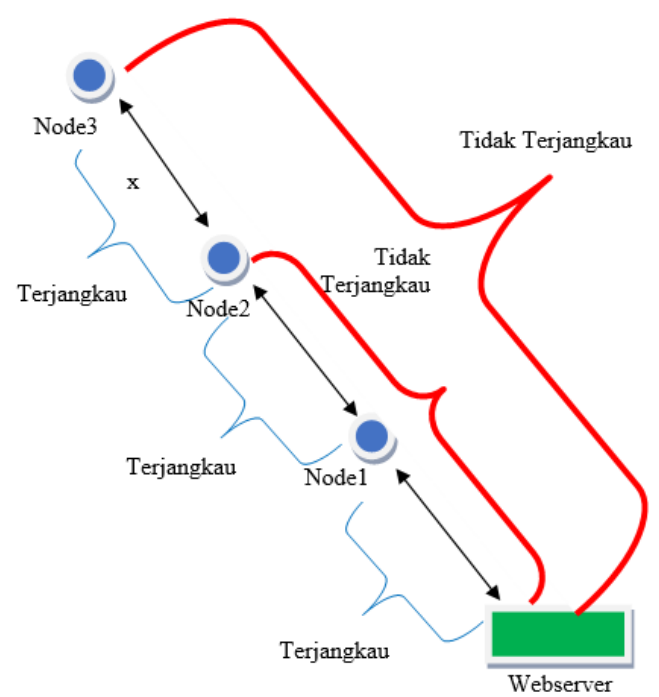

Gambar 5 Pengujian Komunikasi Wireless Sensor Network

akan mengirimkan sinyal ke node sensor yang lebih dekat. Kemudian node sensor yang lebih dekat mengirimkan ulang sinyal tersebut. Hal ini dilakukan berulang sampai sinyal kebakaran sampai pada webserver.

Untuk membuat komunikasi antara node sensor dan webserver dalam mengirimkan sinyal kebakaran serta jangkauan node sensor dekat dan node sensor jauh dalam proses komunikasi, maka dalam penelitian ini dibuat 3 buah node sensor dan sebuah webserver. Node sensor tersebut diberi nama node 1 , node 2 , dan node 3 . Dalam pengujian tersebut nantinya setiap node sensor, yaitu node 1, node 2, dan node 3 dapat mengirimkan data sinyal kebakaran kepada webserver. Skema pengujian komunikasi wireless sensor network tersebut dapat dilihat pada gambar 5 .

\section{Diagram Blok Node Sensor}

Secara umum node sensor terdiri atas power suplai, sensor, mikrokontroller pengolah data, modul komunikasi radio dan antena. Pada penelitian ini bagian dari node sensor yang diteliti difokuskan pada proses komunikasi. Diagram blok node sensor dapat dilihat pada gambar 6.

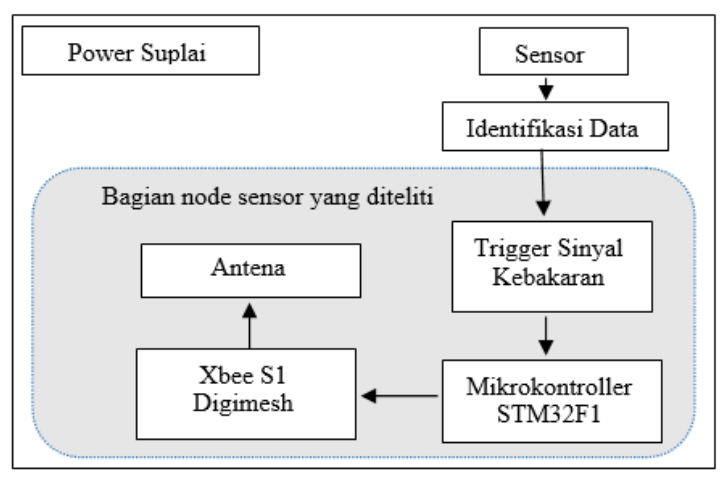

Gambar 6 Diagram Blok Node Sensor 


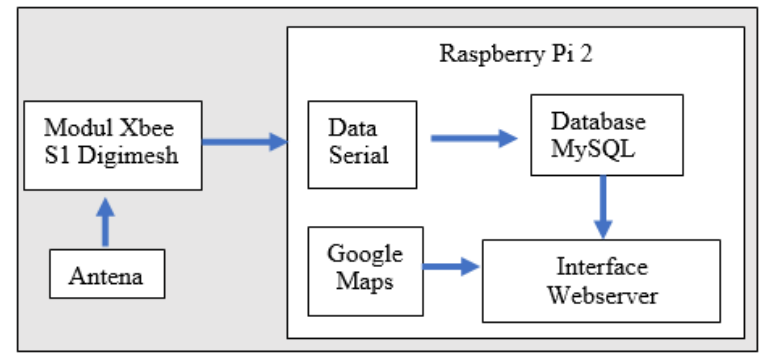

Gambar 7 Diagram Blok Webserver

\section{Diagram Blok Webserver}

Webserver merupakan sebuah pusat data dimana node 1 , node 2, dan node 3 akan mengirimkan data sinyal kebakaran agar sampai kepada webserver. Webserver ini diimplementasikan ke dalam hardware Raspberry pi2. Pada webserver ini semua data sinyal kebakaran yang diterma oleh webserver disimpan kedalam sebuah database. Webserver ini juga bertugas untuk menampilkan database mengenai kondisi kebakaran dengan interface yang dapat memetakan area yang terdampak kebakaran kedalam sebuah peta. Dengan pemetaan kebakaran ini diharapkan user dapat mengetahui area kebakaran secara efisien dan menarik. Diagram blok pada webserver ditunjukkan pada gambar 7.

\section{HASIL PENGUJIAN}

Pada bab ini, dipaparkan mengenai hasil realisasi desain node sensor dan webserver serta hasil pengujian untuk memetakan kebakaran.

\section{A. Realisasi Node Sensor}

Realisasi node sensor terdiri atas power supply, trigger sinyal kebakaran, mikrokontroller STM32f103c8, modul komunikasi xbee s1 digimesh, serta antena. Node sensor tampak dalam terlihat seperti gambar 8. Node sensor tampak luar terlihat pada gambar 9.

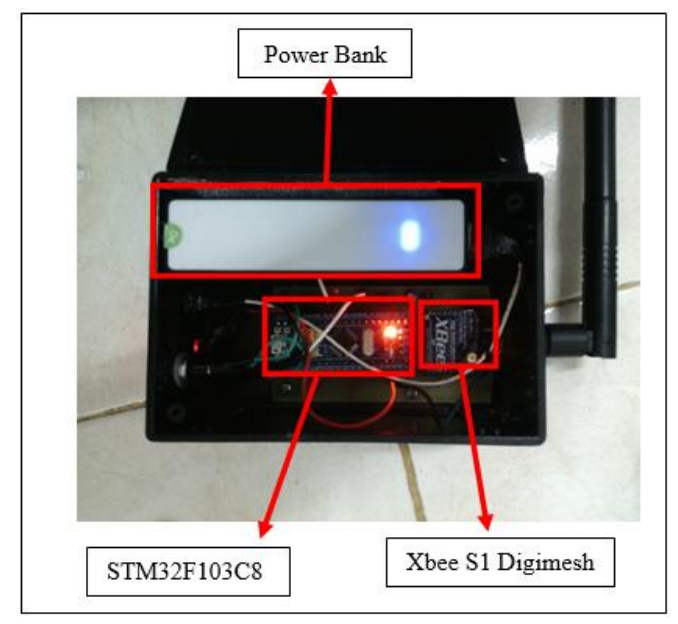

Gambar 8 Node Sensor Tampak Dalam

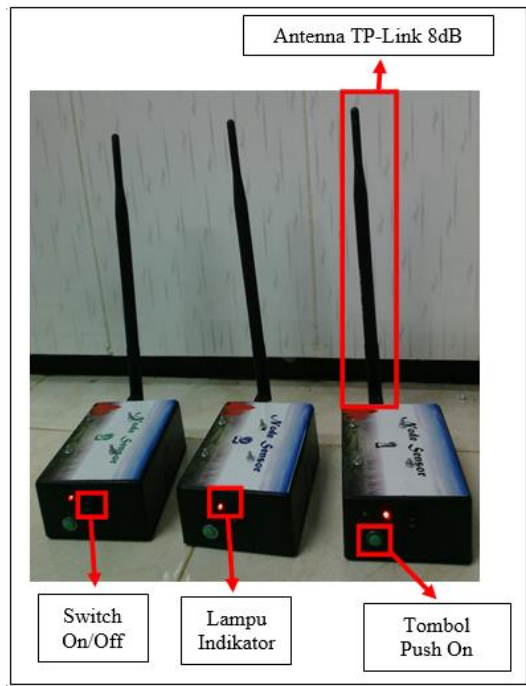

Gambar 9 Node Sensor Tampak Luar

\section{B. Realisasi Webserver}

Realisasi webserver terdiri atas power supply, raspberry pi2, modul komunikasi xbee s1 digimesh, serta antena. Realisasi webserver dapat dilihat pada gambar 10. Tampilan interface dari webserver dapat dilihat dengan menghubungkan webserver pada sebuah komputer. Kemudian dilihat pada web browser google chrome seperti pada gambar 11.

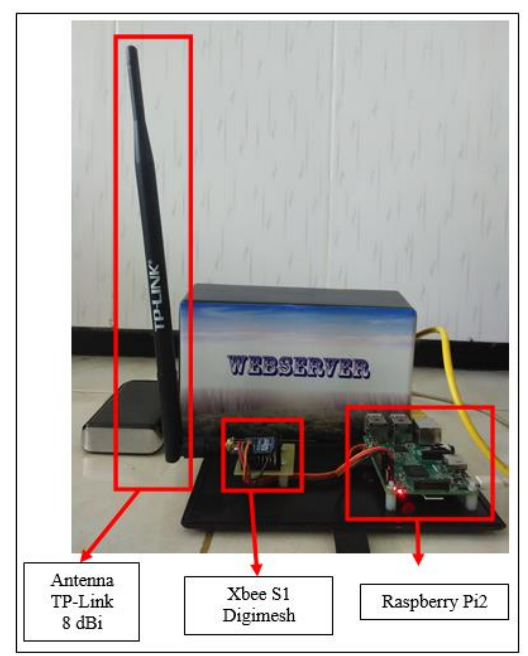

Gambar 10 Realisasi Webserver

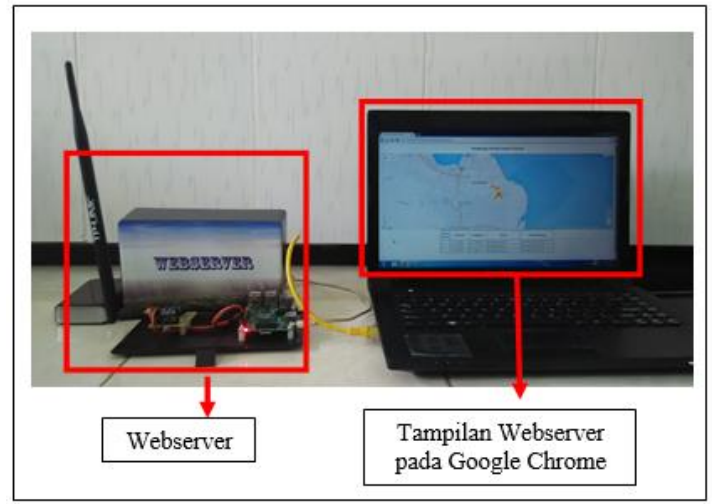

Gambar 11 Tampilan webserver dilihat melalui komputer 


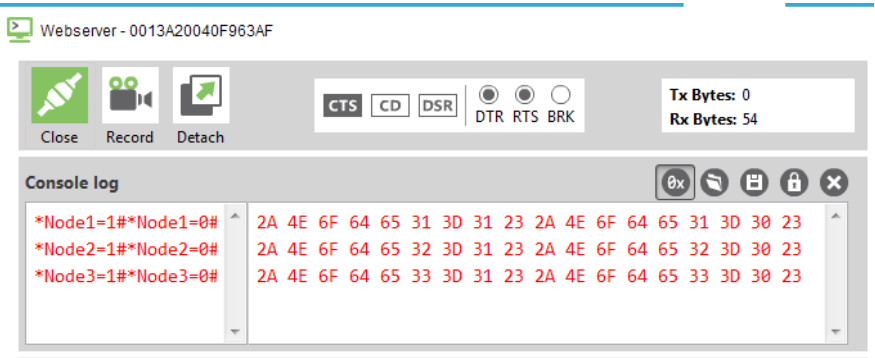

Gambar 12 Hasil Pengiriman Sinyal Kebakaran

\section{Pengujian Pengiriman Sinyal Kebakaran}

Setiap node sensor, yaitu node sensor 1, node sensor 2, dan node sensor 3 mengirimkan akan mengirimkan sinyal kebakaran. Hasil pengiriman sinyal kebakaran dapat dilihat pada gambar 12 .

\section{Pembacaan Data Node Sensor Pada Database}

Sinyal kebakaran yang diterima oleh webserver akan disimpan kedalam database. Hasil database pada webserver dapat dilihat pada gambar 13 .

\begin{tabular}{|c|c|c|c|c|c|c|c|}
\hline Browse & Ins & Structure & 回 & SQL $\quad$ Q & Search 할 & $\therefore$ Insert $\rightarrow$ Expo & ort $\Leftrightarrow$ Import \\
\hline$T \rightarrow$ & & & no & Iatitude & longitude & status & waktu_datang \\
\hline Edit & क्रें Copy & (1) Delete & 162 & -7.2754838 & 112.7868656 & Kebakaran Kecil & $2016-05-2220.03 \cdot 38$ \\
\hline 8 Edit & 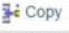 & O Delete & 163 & -7.2754838 & 112.7868656 & Kebakaran Sedang & $2016-05-22$ 20:03:44 \\
\hline 2 Edt & 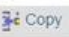 & (9) Delete & 164 & -7.2754838 & 112.7868656 & Kebakaran Kecil & $2016-05-22 \quad 20.07 .57$ \\
\hline 2 Edit & z̧ $i$ Copy & Delete & 165 & -7.2754838 & 112.7868656 & Kebakaran Sedang & $2016-05-2220 \cdot 08 \cdot 04$ \\
\hline$\partial$ Edit & Ficopy & (9) Delete & 166 & -7.2754838 & 112.7868656 & Kebakaran Besar & $2016-05-2220: 10: 11$ \\
\hline 2 Edit & 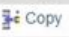 & (9) Delete & 167 & -7.2754838 & 112.7868656 & Kebakaran Kecil & $2016 \cdot 05-22 \quad 20: 10 \cdot 37$ \\
\hline$D$ Edit & sequ copy & Delete & 168 & .72754838 & 112.7868656 & Kebakaran Sedang & $2016-05-22 \quad 20 \cdot 18 \cdot 32$ \\
\hline 2 Edit & 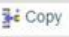 & Delete & 169 & -7.2754838 & 112.7868656 & Baik & $2016-05-2220: 18: 56$ \\
\hline$\gamma$ Edir & 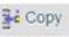 & (9) Delete & 170 & -7.2754838 & 112.7868656 & Kebakaran Besar & $2016-05-2220: 19: 10$ \\
\hline 2 Edit & ఫ్ర్యं Copy & (2) Delete & 171 & -7.2754838 & 112.7868656 & Kebakaran Kecil & 2016-05-22 20:34:19 \\
\hline 2 Edit & 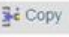 & Delete & 172 & -7.2754838 & 112.7868656 & Kebakaran Kecil & $2016-05-2220: 36 \cdot 51$ \\
\hline 2 Edit & ఫ్pi Copy & Delete & 173 & -7.2754838 & 112.7868656 & Kebakaran Kecil & $2016-05-22$ 21:15:16 \\
\hline$D$ Edit & స్tic Copy & Delete & 174 & -7.2754838 & 112.7868656 & Kebakaran Kecil & $2016-05-22 \quad 21: 15.20$ \\
\hline 2 Edit & ఫ్రా: Copy & Delete & 175 & -7.2754838 & 112.7868656 & Kebakaran Kecil & 2016-05-22 21:17:06 \\
\hline$D$ Edit & 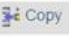 & 10 Delete & 176 & -7.2754838 & 112.7868656 & Kebakaran Sedang & $2016-05-22 \quad 21: 17: 10$ \\
\hline 2 Edit & क्रें Copy & Delete & 177 & -7.2754838 & 112.7868656 & Kebakaran Kecil & $2016-05-2221: 29 \cdot 57$ \\
\hline$D$ Edit & 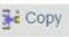 & Delete & 178 & -7.2754838 & 112.7868656 & Kebakaran Kecil & $2016-05-2221.30 .13$ \\
\hline 2 Edit & ్ㅟ: Copy & Delete & 179 & -7.2754838 & 112.7868656 & Baik & 2016-05-22 21:39:39 \\
\hline$D$ Edit & $\underset{7}{\not} i$ Copy & Delete & 180 & -72754838 & 112.7868656 & Kebakaran Kecil & $2016-05-22 \quad 22: 28: 19$ \\
\hline 2 Edit & क्षैi Copy & D Delete & 181 & -7.2754838 & 112.7868656 & Kebakaran Kecil & 2016-06-09 07:00:37 \\
\hline
\end{tabular}
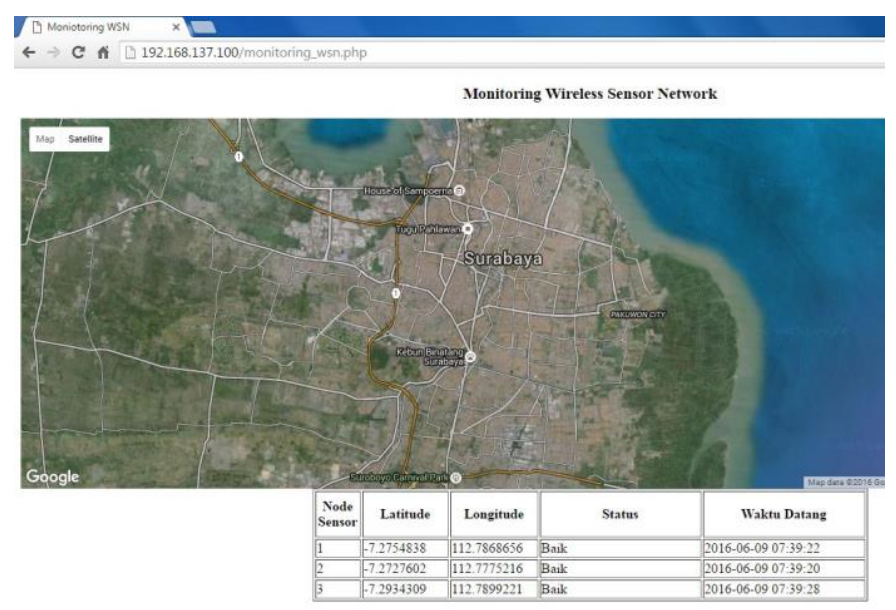

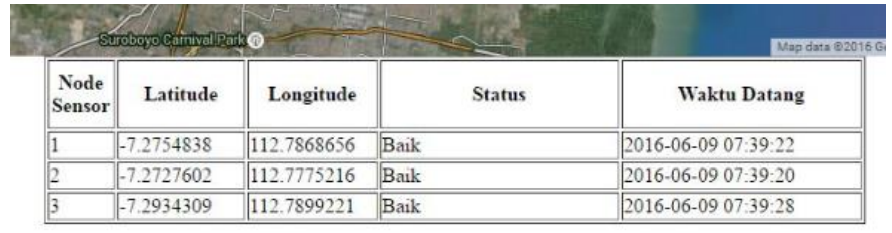

Gambar 15 Detail Informasi Node Sensor

LWsn.php

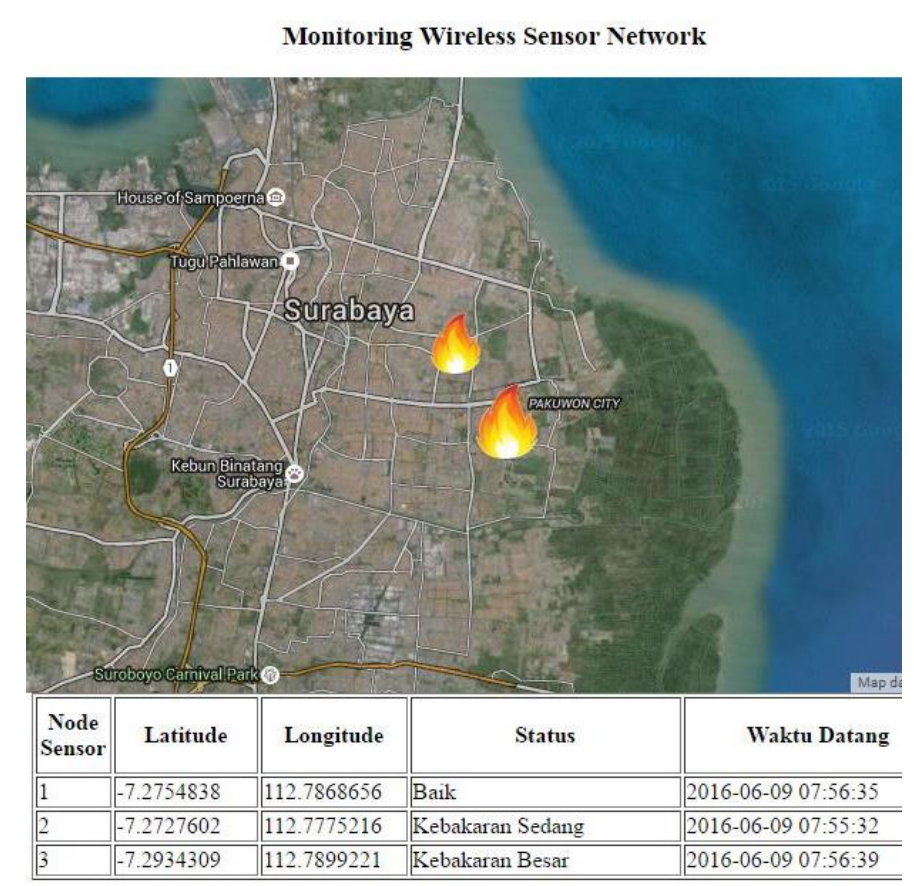

Gambar 16 Tampilan Webserver saat Terjadi Kebakaran

\section{E. Hasil Tampilan Pemetaan Kebakaran Pada Webserver}

Interface pada webserver untuk pemetaan api diintegrasikan dengan google maps. Hal ini dapat mempermudah user untuk mengetahui area kebakaran. Untuk menambah detail dari posisi kebakaran, maka ditambahkan tabel yang berada pada bagian bawah website. Koordinat dari setiap node sensor ditunjukkan pada kolom latitude dan longitude. Status dari setiap node sensor terdapat pada kolom "Status". Sedangkan kolom waktu datang menunjukkan waktu node sensor mendeteksi kebakaran. Tampilan webserver saat kondisi baik dapat dilihat pada gambar 14. Detail informasi lokasi dan kondisi node sensor dapat dilihat pada gambar 15 . Serta tampilan webserver saat terjadi kebakaran dapat dilihat pada gambar 16.

\section{F. Pengujian Komunikasi Wireless Sensor Network}

Pengujian komunikasi yang pertama dilakukan adalah mengukur jarak maksimum antara 2 buah modul xbee s1 digimesh. Pengukuran dilakukan secara Line of Sight dari jarak 0 meter. Kemudian meningkat lebih jauh dengan jarak 2 meter. Hasil pengujian jarak komunikasi dapat dilihat pada tabel 2. Dari data tersebut didapatkan jarak terjauh antara 2 modul xbee s1 digimesh adalah 28 meter dengan sinyal RSSI local sebesar $-57 \mathrm{dBm}$ dan sinyal RSSI remote sebesar $-60 \mathrm{dBm}$. 
Tabel 2

Pengujian Jangkauan antara 2 Modul Xbee S1 Digimesh

\begin{tabular}{cccc}
\hline \hline \multirow{2}{*}{ No } & \multirow{2}{*}{ Jarak } & \multicolumn{2}{c}{ Sinyal } \\
\cline { 3 - 4 } 1 & $0 \mathrm{~m}$ & Local $(\mathrm{dBm})$ & Remote $(\mathrm{dBm})$ \\
2 & $2 \mathrm{~m}$ & $-33 \mathrm{dBm}$ & $-35 \mathrm{dBm}$ \\
3 & $4 \mathrm{~m}$ & $-48 \mathrm{dBm}$ & $-40 \mathrm{dBm}$ \\
4 & $6 \mathrm{~m}$ & $-48 \mathrm{dBm}$ & $-50 \mathrm{dBm}$ \\
5 & $8 \mathrm{~m}$ & $-48 \mathrm{dBm}$ & $-51 \mathrm{dBm}$ \\
6 & $10 \mathrm{~m}$ & $-50 \mathrm{dBm}$ & $-50 \mathrm{dBm}$ \\
7 & $12 \mathrm{~m}$ & $-52 \mathrm{dBm}$ & $-52 \mathrm{dBm}$ \\
8 & $14 \mathrm{~m}$ & $-55 \mathrm{dBm}$ & $-57 \mathrm{dBm}$ \\
9 & $16 \mathrm{~m}$ & $-55 \mathrm{dBm}$ & $-56 \mathrm{dBm}$ \\
10 & $18 \mathrm{~m}$ & $-56 \mathrm{dBm}$ & $-58 \mathrm{dBm}$ \\
11 & $20 \mathrm{~m}$ & $-55 \mathrm{dBm}$ & $-58 \mathrm{dBm}$ \\
12 & $22 \mathrm{~m}$ & $-56 \mathrm{dBm}$ & $-58 \mathrm{dBm}$ \\
13 & $24 \mathrm{~m}$ & $-57 \mathrm{dBm}$ & $-59 \mathrm{dBm}$ \\
14 & $26 \mathrm{~m}$ & $-57 \mathrm{dBm}$ & $-60 \mathrm{dBm}$ \\
15 & $28 \mathrm{~m}$ & $-57 \mathrm{dBm}$ & $-60 \mathrm{dBm}$ \\
16 & $30 \mathrm{~m}$ & Tidak terdeteksi & Tidak terdeteksi \\
\hline \hline
\end{tabular}

Tabel 3

Pengujian Komunikasi WSN

\begin{tabular}{cccccc}
\hline \hline & & & & \multicolumn{2}{c}{ Sinyal } \\
\cline { 5 - 6 } No & Penerima & Pengirim & Jarak & $\begin{array}{c}\text { Local } \\
(\mathrm{dBm})\end{array}$ & $\begin{array}{c}\text { Remote } \\
(\mathrm{dBm})\end{array}$ \\
\hline 1 & Webserver & Node 1 & $20 \mathrm{~m}$ & -59 & -57 \\
2 & Webserver & Node 2 & $40 \mathrm{~m}$ & -57 & -52 \\
3 & Webserver & Node 3 & $60 \mathrm{~m}$ & -57 & -52 \\
\hline \hline
\end{tabular}

Tabel 4

Pengujian Tranfer Data Node Sensor

\begin{tabular}{cc}
\hline \hline Node Sensor & Rata-rata kecepatan data \\
\hline 1 & $3.63 \mathrm{Kbps}$ \\
2 & $2.91 \mathrm{Kbps}$ \\
3 & $3.11 \mathrm{Kbps}$ \\
\hline \hline
\end{tabular}

Selanjutnya dilakukan pengujian apakah node sensor yang berada pada jarak yang jauh dapat mengirimkan sinyal kepada webserver. Node sensor 2 terletak 40 meter dari webserver (tidak terjangkau) dan Node sensor 3 terletak 60 meter dari webserver (tidak terjangkau). Namun antara node sensor 1 , node sensor 2, dan node sensor 3 masih dapat berkomunikasi karena antar modul xbee masih berjarak 20 meter. Hasil pengujian didapatkan node sensor 1 , node sensor 2, dan node sensor 3 dapat mengirim data dengan baik. Hasil pengujian ini dapat dilihat pada tabel 3 .

Pengujian selanjutnya yaitu mengukur kecepatan transfer data dari node sensor 1 , node sensor 2 , dan node sensor 3 kepada webserver. Transfer data dilakukan secara kontinyu selama 60 detik. Selanjutnya diambil nilai rata-rata kecepatan transfer data dari setiap node sensor. Hasil pengujian dapat transfer data node sensor dilihat pada tabel 4.

\section{KESIMPULAN}

Pada penelitian ini telah dibuat dan dirancangan desain wireless sensor network (WSN) dan webserver yang dapat memetakan titik api untuk aplikasi kebakaran hutan. Pengujian pengiriman serial node sensor menunjukkan bahwa node sensor dapat mengirim sinyal kebakaran kecil, kebakaran sedang, dan kebakaran besar. Webserver dapat menerima data sinyal kebakaran dari ketiga node sensor dan memasukkannya ke dalam database. Kemudian webserver dapat memetakan area kebakaran pada suatu peta yang terintegrasi dengan google maps. Kondisi node sensor dapat direpresentasikan pada peta melalui gambar api. Saat kondisi baik, maka pada peta tidak terdapat gambar api. Sedangkan saat terjadi kebakaran, pada peta dapat menampilkan gambar api sesuai dengan kondisi kebakaran kecil, kebakaran sedang, atau kebakaran besar. Lokasi node sensor dapat dilihat secara mudah pada tabel webserver. Pengujian jarak komunikasi antara 2 buah modul RF xbee $\mathrm{S} 1$ digimesh menunjukkan jarak terjauh 28 meter dengan sinyal RSSI pada local device sebesar $-57 \mathrm{dBm}$ dan RSSI pada remote device sebesar $-60 \mathrm{dBm}$. Pengujian komunikasi secara WSN pada 3 buah node sensor dengan webserver, pada jarak node 120 meter dari webserver, node 240 meter dari webserver, dan node $360 \mathrm{~m}$ dari webserver secara Line of Sight (satu jalur lurus) menunjukkan sinyal kebakaran dari node1, node2, dan node 3 dapat diterima dengan baik oleh webserver.

\section{DAFTAR PUSTAKA}

[1] Dephut. 2015. Pedoman Pengendalian Kebakaran Hutan dan Lahan. Diakse di < www.dephut.go.id> pada Januari 2016.

[2] Alkhatib, Ahmad. 2012. Wireless Sensor Network for Forest Fire Detection System - Seminar. Newport:University of Wales.

[3]International, Digi. 2016. Xbee Familiy Features Comparison. Diakses di <digi.com> pada Feburari 2016

[4] International, Digi. 2008. Wireless Mesh Networking. Diakses di <digi.com> pada Februari 2016

[5] Libellium. 2012. Waspmote Digimesh Networking Guide. Libelium Comunicaciones Distribuidas S.L

[6] STMicroelectronics. 2015. Datahseet STM32F103x8.

[7] Raspberry pi 2. Diakses di <www.raspberrypi.org > pada Februari 2016 